\title{
Child-Pugh Class B9
}

National Cancer Institute

\section{Source}

National Cancer Institute. Child-Pugh Class B9. NCI Thesaurus. Code C146794.

A total score of 9 for hepatic function, corresponding to class B in the Child-Pugh classification. 